\title{
STUDIES OF A PRIMARY INFECTIOUS DISEASE IN THE SO-CALLED FUNGUS DISEASE OF EELS.*
}

\author{
Syuzo EGUSA and Tomoko NISHIKAWA** \\ (Received Sep. 3, 1965)
}

In a previous paper ${ }^{11}$ indirect evidence was reported to support the concept that in the so-called fungus disease of eels (Anguilla japonica) fish become primarily infected with a disease which is considered to be of bacterial origin and fungus infection occurs secondarily. The present investigation was initiated to obtain direct evidence as to this problem.

\section{Bacteriological examination of fungus-diseased eels.}

\section{Material.}

Fungus-diseased eels were subjected to bacteriological examination in an attempt to determine whether or not the primary disease in question was of bacterial origin and, if so, to isolate the causal agent. The material used consisted of diseased eels collected from aquaria of our laboratory and those from eel-culturing ponds in Shizuoka Prefecture (Table 1).

\section{Isolation of Aeromonas liquefaciens from diseased eels.}

The method adopted for bacteriological examination was to cut small pieces of tissue from skin lesions and viscera (liver and kidney) of each fish and introduce them into nutrient broth. All materials were taken from living fish under anaethesia with $1.5 \%$ urethan solution. The cultures were incubated for 24 to 48 hours at 20 to $25^{\circ} \mathrm{C}$. Primary cultures from skin lesions almost always contained several species of bacteria. Viscera from diseased fish usually yielded one or two species. These primary cultures were plated on nutrient agar.

Throughout the cultures from skin lesions and viscera of many diseased fish colonies of a certain type almost regularly appeared on agar. The colonies were circular, entire, raised, smooth, moist and pale brown or grayish white in color. No pigment was produced. The colonies contained motile, monotrichous, Gram-negative bacilli of 0.4 to 0.8 by 0.9 to $3.0 \mu$ in size. The bacteria grew well on MacConkey agar. On horse blood agar the colonies were hemolytic ( $\beta$-hemolysis).

* Studies on Saprolegniasis of the Eel.-III.

* Department of Fishery, Faculty of Agriculture, the University of Tokyo, Tokyo, Japan. (江草周三・西川朋子, 東京大学擃学部) 
Table 1. Material.

\begin{tabular}{|c|c|c|c|c|c|}
\hline \multirow{2}{*}{\multicolumn{3}{|c|}{ Source of material }} & \multirow{2}{*}{$\begin{array}{l}\text { Date } \\
\text { of } \\
\text { collection }\end{array}$} & \multicolumn{2}{|c|}{ Number of fish examined } \\
\hline & & & & bacteriologically & anatomically \\
\hline Tanks & \multicolumn{2}{|c|}{$\begin{array}{l}\text { Experimental aquaria of Exps. I-7, } \\
9,12 \text { and } 14 \text { and retaining tanks of } \\
\text { Materials } 5,6,7,10 \text { and } 12 \text { in a } \\
\text { previous investigation. } 1 \text {. }\end{array}$} & $\begin{array}{l}\text { May, } 1963 \sim \\
\text { Jan., } 1965 .\end{array}$ & $\begin{array}{c}36 \\
(18 \sim 42 \mathrm{~cm} .)^{*}\end{array}$ & - \\
\hline \multirow{5}{*}{ Pond** } & $\begin{array}{l}\text { Survey } \\
\text { number }\end{array}$ & $\begin{array}{l}\text { Location and number of } \\
\text { ponds from which diseased } \\
\text { fish were collected. }\end{array}$ & & & \\
\hline & 1 & $\begin{array}{l}\text { Shinohara (2), } \\
\text { Bentenjima (1), } \\
\text { Kawajiri (2), Yaizu (2) }\end{array}$ & Jan. $24-\frac{26}{1964}$ & $\begin{array}{c}22 \\
(19 \sim 49 \mathrm{~cm} .)\end{array}$ & $\begin{array}{c}83 \\
(17 \sim 49 \mathrm{~cm} .)\end{array}$ \\
\hline & 2 & $\begin{array}{l}\text { Shinohara (3), Arai (1), } \\
\text { Fukude (1), Sachiura (1), } \\
\text { Kawajiri (4), Yaizu (2) }\end{array}$ & April $\underset{19-17}{1964}$ & $\begin{array}{c}18 \\
(28 \sim 53 \mathrm{~cm} .)\end{array}$ & $\begin{array}{c}83 \\
(26 \sim 53 \mathrm{~cm} .)\end{array}$ \\
\hline & 3 & $\begin{array}{l}\text { Shinohara (2), Shinzu (1), } \\
\text { Araibenten (1), } \\
\text { Bentenjima (1) }\end{array}$ & April $23-24$ & $\begin{array}{c}9 \\
(28 \sim 40 \mathrm{~cm} .)\end{array}$ & $\begin{array}{c}17 \\
(21 \sim 43 \mathrm{~cm} .)\end{array}$ \\
\hline & 4 & $\begin{array}{l}\text { Yaizu (3), Kawajiri (2), } \\
\text { Oigawa (2) }\end{array}$ & May $19-20$, & $(22 \sim 54 \mathrm{~cm})$. & $\begin{array}{c}20 \\
(20 \sim 54 \mathrm{~cm} .)\end{array}$ \\
\hline
\end{tabular}

* Body length of fish examined.

** In January and April, 1964 and April and May, 1965, severe epizootics of "fungus disease" broke out in many eel-culturing ponds in Shizuoka Prefecture. Diseased fish were collected from some of the ponds where epizootics were in progress.

Table 2. Biochemical characteristics of 18 cultures of Aeromonas liquefaciens isolated from diseased eels.

\begin{tabular}{|c|c|c|c|c|c|}
\hline Test & No. + & No. - & Test & No. + & No. - \\
\hline Carbohydrate utilization & & & Production of & 18 & 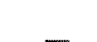 \\
\hline Glucose & $18^{*}(\mathrm{AG})^{* *}$ & - & 2, 3-butanediol & 18 & - \\
\hline Fructose & $18(\mathrm{AG})$ & - & Hydrosis of starch & 18 & - \\
\hline Galactose & $18(\mathrm{AG})$ & - & Voges-Proskauer test & 18 & - \\
\hline Arabinose & $9(\mathrm{AG})$ & 6 & Methyl red reaction & 13 & 5 \\
\hline & $3(\mathrm{~A})$ & & $\begin{array}{l}\text { Presence of } \\
\text { cytochrome oxidase }\end{array}$ & 18 & - \\
\hline Rhamnose & $2(\mathrm{AG})$ & 16 & Production of hydrogen & & \\
\hline Xylose & - & 18 & sulfide (Kliegler) & - & 18 \\
\hline Sucrose & $18(\mathrm{AG})$ & - & " Motility & & \\
\hline Lactose & 1 (A) & 17 & sulfide) & 18 & - \\
\hline Raffinose & - & 18 & Production of indole & 18 & - \\
\hline Dextrin & $18(\mathrm{AG})$ & - & Utilization of citrate & 15 & 3 \\
\hline Starch & $18(\mathrm{AG})$ & - & Reduction of nitrate & 18 & - \\
\hline Mannit & $18(\mathrm{AG})$ & - & Liquefaction of gelatin & 18 & - \\
\hline
\end{tabular}

* The figures represent the number of strains that gave positive and negative reactions.

** AG, acid and gas; $A$, acid only. 
Because of its regular occurrence in diseased fish attention was concentrated on this bacterium and 18 cultures isolated from diseased eels collected in different areas and at different times were subjected to the usual biochemical reactions. The biochemical characteristics listed in Table 2, in addition to its polar monotrichous flagellation, place the organism in the genus Aeromonas.

Bergey's Manual (1957)2 lists the three motile species, A. liquefaciens, A. punctata and $A$. hydrophila. Opinion is divided, however, among investigators regarding the taxonomy of the motile species of this genus. EwING et $\mathrm{al}^{3)}$ claimed that the name $A$. hydrophila CHISTER (STANIER, 1943) has priority over others and the specific epithets should be considered to be biotypes within a single species $A$. hydrophila. While EDDY ${ }^{4)}$ suggested that the specific epithet liquefaciens would appear to have priority. BULLOCK ${ }^{5}$, and SNIESZKO and BULLOCK ${ }^{6)}$ expressed the opinion that bacteria causing most of the outbreaks of infectious dropsy and hemorrhagic septicemia of warm water fish, red mouth of trout, red sore disease of pike and red leg disease of frogs should be classified as type species A. liquefaciens. In accordance with their view, "for the sake of clarity' and unity the name $A$ liquefaciens will be here adopted.

Ten strains of this bacterium were tested for pathogenicity on eels. The cultures, grown for 24 hours at about $25^{\circ} \mathrm{C}$ on nutrient agar, were injected intramuscularly into healthy eels at a rate of $1.0 \mathrm{mg}$. of bacteria suspended in saline per $100 \mathrm{gr}$. body weight. The injection caused the development of a swollen, necrotic lesion at the site of inoculation and eroded areas, usually accompanied with petechiae, on various parts of the head, body or fins and killed the fish in one to two weeks (at 14 to $20^{\circ} \mathrm{C}$.). The strains identical with those inoculated were isolated from skin lesions and viscera. No appreciable difference in pathogenicity was observed among the strains tested.

In August, 1964, rabit antisera were prepared against 14 strains representative of various eel-culturing areas in Shizuoka Prefecture. These antisera were conveniently used in identifying the species by means of a slide agglutination test in the two surveys of the following year.

\section{Gross anatomy of diseased eels collected from eel-culturing ponds.}

Gross anatomical examination revealed that the majority of the diseased fish examined had eroded areas, sometimes blood-colored, or discolored necrotic areas, usually surrounded by zones with a distinct reddish tinge and occasionally extended deep into the muscles, on some part of the head, body or fins. These lesions were mostly fungused, but some of them were free from fungus infection. In part of the diseased fish the anal fin, pectoral fin, vent or the underside of the body, particularly of the belly, showed a marked red color. The reddening was due partly to widening of the blood vessels and partly to hemorrhages. Petechiae or ecchymoses were 
occasionally noted on the surface of the body. Apart from these external symptoms, internal gross abnormalities such as congestion of the liver, spleen or kidney, and inflammation of the intestine or stomach, were observed in almost all the fish examined.

Many of the diseased fish were heavily infected with fungus. There were, however, some that were not infected with it. Two hundred and three fish in total were examined for the presence of fungus in the 4 surveys. The examination showed that 43 fish $(21 \%)$ had no signs of fungus infection, in spite of the fact that of the 43 fish 40 presented some of the external and internal signs mentioned above (Table 3).

The fish examined were divided into 3 groups on the basis of the severity of fungus infection and the incidence of fish which showed abnormal signs externally and/or internally was determined. The results were summarized in Table 3 . It is worthy of notice that fish which showed none of the aforementioned abnormalities reached only $3 \%$ of the total fish examined, as contrasted with the high percentage of 21 in case of fungus-uninfected fish.

Table 3. Gross anatomical features of diseased eels collected from ponds where "fungus disease" was prevailing.

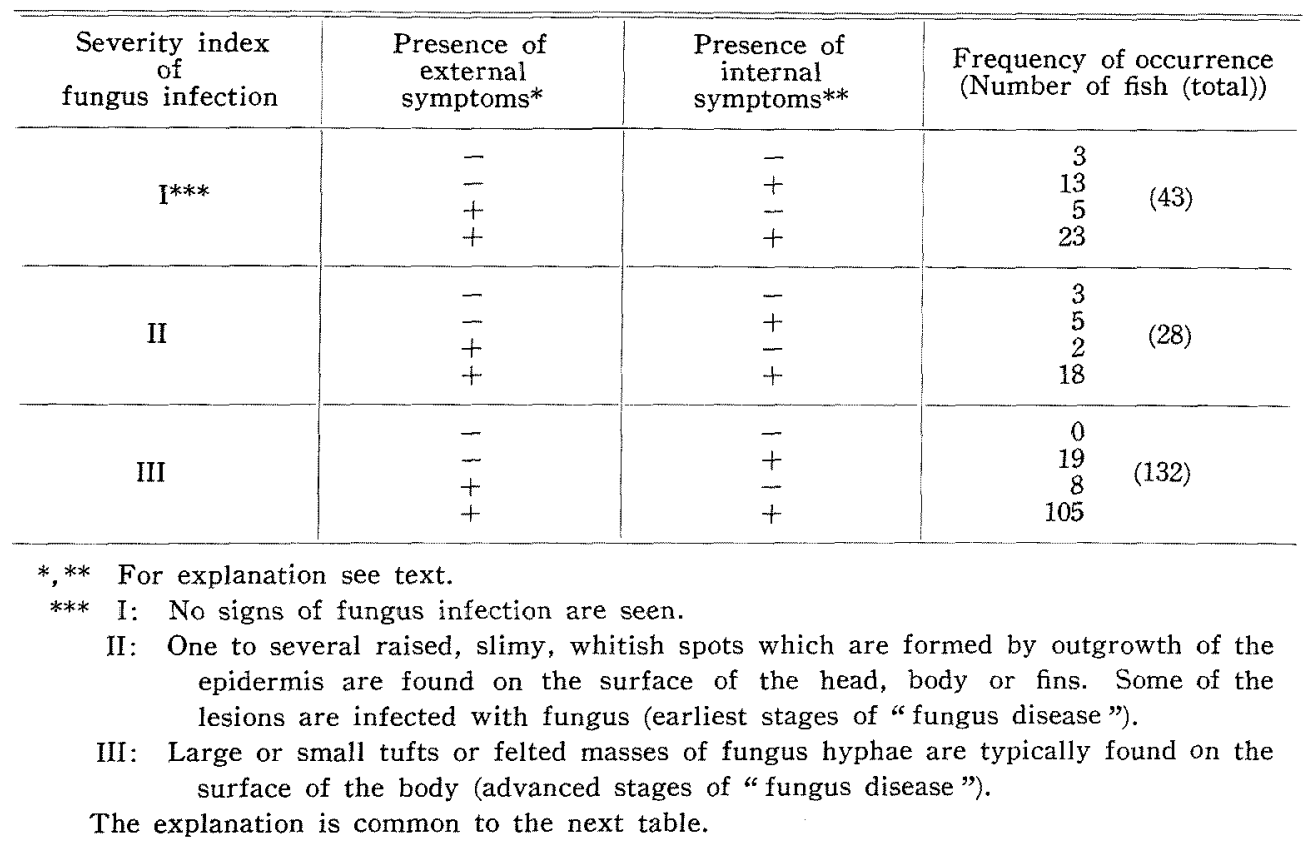

\section{Severity of fungus infection and incidence of Aeromonas liquefaciens.}

Ninety seven fish in total, of which 16 were healthy, were examined for the presence of $A$. liquefaciens. They were classified into 3 categories according to the 
same criterion as before. Incidence of $A$. liquefaciens in the skin lesions and/or the viscera of the fish belonging to each category was determined. The results are given in Table 4.

The table shows that $A$. liquefaciens was isolated from all the fungus-diseased eels examined, except two with slight symptoms. Of the 81 diseased fish in total 68 harboured $A$. liquefaciens in both skin lesions and viscera. While fish in which A. liquefaciens was isolated only from skin lesions and those in which the bacterium was carried only in viscera were 6 and 5, respectively. Of these 11 fish 8 were in incipient stages of fungus disease. It is a matter of interest that of the 16 healthy fish, showing any signs of gross abnormalities neither externally nor internally, 6 harboured $A$. liquefaciens in their visera. It seems likely that they were in the incubation stage.

Table 4. Incidence of Aeromonas liquefaciens in the skin lesions and viscera of fungusdiseased eels collected from eel-culturing ponds and experimental aquaria.

\begin{tabular}{|c|c|c|c|c|c|c|c|}
\hline \multirow{3}{*}{$\begin{array}{l}\text { Severity index* } \\
\text { of } \\
\text { fungus infection }\end{array}$} & \multirow{3}{*}{$\begin{array}{c}\text { Parts of the fish body } \\
\text { harbouring } \\
\text { Aeromonas liquefaciens }\end{array}$} & \multicolumn{5}{|c|}{ Number of fish from } & \multirow{3}{*}{ Total } \\
\hline & & \multirow{2}{*}{ tanks } & \multicolumn{4}{|c|}{ ponds } & \\
\hline & & & 1 & $\begin{array}{c}\text { rvey } \\
2\end{array}$ & $\underset{3}{\mathrm{uml}}$ & 4 & \\
\hline \multirow{2}{*}{ I } & None & 8 & 2 & - & - & - & $10^{* * *}$ \\
\hline & Viscera** & 6 & - & - & - & - & 6 \\
\hline \multirow{4}{*}{ II } & None & 1 & - & - & - & 1 & 2 \\
\hline & Skin lesions & 4 & - & - & - & - & 4 \\
\hline & Viscera & 1 & 2 & - & - & 1 & 4 \\
\hline & Skin lesions and viscera & 6 & 2 & - & 2 & 1 & 11 \\
\hline \multirow{4}{*}{ III } & None & - & - & - & - & - & 0 \\
\hline & Skin lesions & - & 1 & 1 & - & - & 2 \\
\hline & Viscera & - & 1 & - & - & - & 1 \\
\hline & Skin lesions and viscera & 10 & 14 & 17 & 7 & 9 & 57 \\
\hline
\end{tabular}

* See Table 3 for definition of severity indices.

** Liver and/or kidney.

*** Abnormal signs were present neither externally nor internally in these 16 fish.

\section{Susceptibility of Aeromonas-infected eels to fungus infection.}

The above results suggest that $A$. liquefaciens may be a causative agent of the primary disease in question. The following attempt was initiated in order to know whether or not eels infected with $A$. liquefaciens become susceptible to fungus infection. 


\section{Material and method.}

Fish used in experiments were healthy eels ranging from 30 to $80 \mathrm{gr}$. in body weight taken from a pond of the Fishery Laboratory of the University of Tokyo. This pond is known to be free of fungus disease ${ }^{1 /}$ and fish from it fail to show the presence of A. liquefaciens. Five groups of eels, each consisting of 4 fish, were inoculated with 2-day-old cultures, grown on agar, of the 5 strains, T-ET, S-10, $\mathrm{K}-29, \mathrm{~K}-60$ and $\mathrm{K}-62$, respectively. Each fish received intramuscularly $0.2 \mathrm{mg}$. of bacteria suspended in saline per $100 \mathrm{gr}$. body weight. Immediately after inoculation each group of fish was introduced into the respective aquarium, where they were exposed for successive 35 days to Saprolegnia parasitica in the same manner as that employed in the previous investigation." In each experiment 4 fish injected with saline were used for controls. Two of them were placed in the auqarium at the start of the experiment (control A). The other 2 were introduced into it 10 days after the start (control B). All the aquaria were supplied with gently flowing tap water. The water temperature during the course of the experiment was 14 to $17^{\circ} \mathrm{C}$.

\section{Results.}

The course of a disease set up by the inoculation of A. liquefaciens (tentatively called "Aeromonas disease") was divided into the following seven exacerbation stages $0 \sim 6$ and three convalescent stages $2^{\prime} \sim 0^{\prime}$ chiefly on the basis of external symptoms: (0) No particular outward signs are present (for several hours after inoculation). (1) Hemorrhage appeared at the site of inoculation. The environs became discolored. (2) The affected area extended and swelled up. Small hemorrhagic spots were occasionally found on the surface of the body. (3) The swelling developed into a dark reddish blister. Surrounding hemorrhage and discoloration were wide and intense. Hemorrhagic spots became apparent on various parts of the body. (4) The blister developed into a large, putrid one filled with a reddish puslike matter. Petechiae and ecchymoses are prominent. The anal fin, pectoral fin and belly often show a red color. The blister occasionally broke open to form a large ulcer (Fig. 1, A). (5) Fish lost equilibrium. External abnormal features became more extensive. (6) Fish succumbed.

There were some fish which began to make progress toward recovery after they once reached the stage 2 or 3 . In these fish the swelling developed at the site of inoculation gradually subsided or burst, leaving a hollow $\left(2^{\prime}\right)$. Hemorrhagic spots which had developed on the surface of the body gradually disappeared. The swelling completely subsided in course of time. A hollow, if it had been formed, reduced in area $\left(1^{\prime}\right)$. Finally every outward sign of abnormality disappeared $\left(0^{\prime}\right)$.

The inoculated fish without exception began to be affected by fungus within a few days after the start of experiments. In these fish fungus developed almost 
anywhere on the surface of the body. There is a tendency for fungus infection tobecome more intense with progression of "Aeromonas disease". Part of the inoculated fish began to turn toward recovery in two or three weeks, as was. mentioned before. In these fish tufts of fungus which had developed on various. parts of the surface of the body disappeared one after another.

Criteria for 4 progressive degrees of severity of fungus infection were determined as follows: (0) No signs of fungus infection are present. (1) Some small tufts of fungus less than a few millimeters in diameter are noted (Fig. 2, B-1). (2) Large (less than about 1 centimeter in diameter) and small tufts of fungue are seen (Fig.

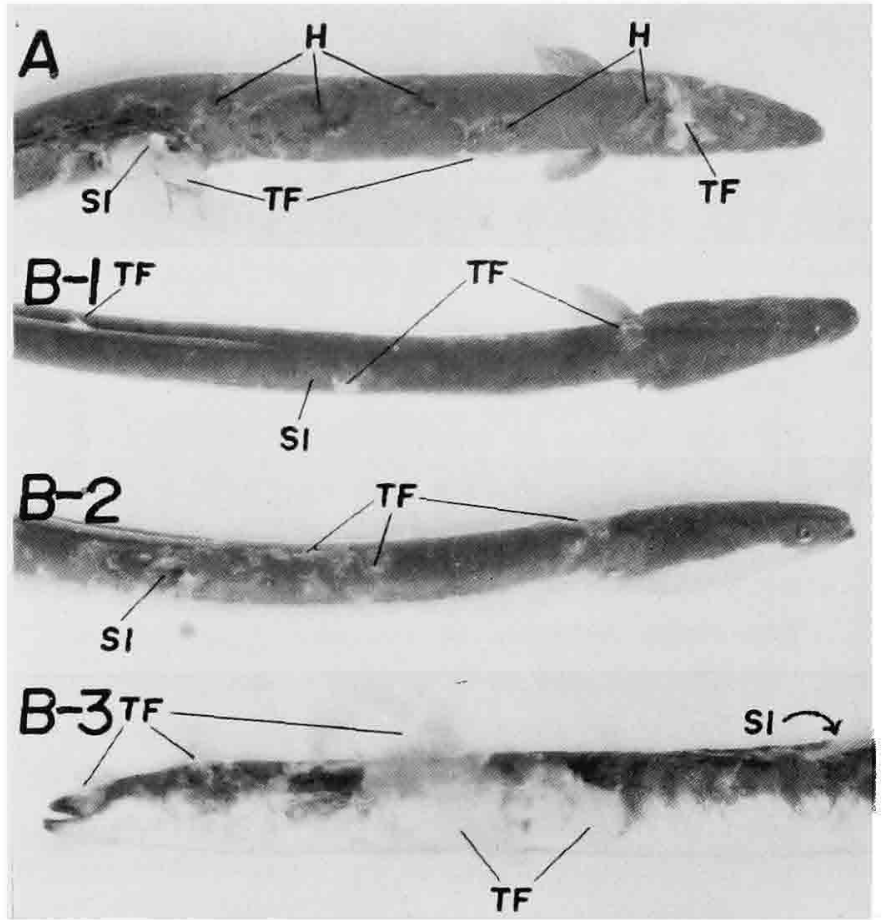

Fig. 1. A. A moribund eel inoculated intramuscularly with $0.2 \mathrm{mg}$. of Aeromonas liquefaciens. 15 days after inoculation.

The fish has several eroded, hemorrhagic areas on the surface of the body, which were mostly covered with masses of fungus hyphase when the fish was in water. Many of the masses fell off at the time of capture.

B. Three phases of fungus infection in eels inoculated with Aeromonas liquefaciens.

(1) One day after inoculation. A few small tufts of fungus are seen at the site of inoculation and other places.

(2) Five days after inoculation. Many large and small tufts of fungus covering skin lesions are present.

(3) Ten days after inoculation. Large tufts of fungus have developed at areas other than the site of inoculation. The site of inoculation is on the opposite side.

SI, site of inoculation; TF, tufts of fungus hyphae; H, hemorrhage. 
2, B-2). (3) Luxuriant growths of fungus covering a large area more than a few square centimeters are found (Fig. 2, B-3).

An example of the results obtained is given in Fig. 2. The other 4 experiments gave similar results. The figure shows that all the inoculated fish became infected with fungus and fungus infection became more intense as "Aeromonas disease" progressed.

As is seen from the figure, one control-A fish and one control-B fish were slightly infected with fungus several days after introduction into the experimental aquarium. In these fish, however, tufts of fungus once developed fell off from the body in course of time and the fish never became fungused again. Of the 20 control fish in total 4 control-A fish and 3 control-B fish were temporarily affected by fungus in this manner. Other 5 control-B fish received many bites under the attack of other fish on the surface of the body during initial several days. Hemorrhagic spots first appeared in the bites and subsequently fungus infection occurred there. With the lapse of time hemorrhage and fungus infection became more intensified and finally the fish died. A. liquefaciens was regularly isolated from the skin lesions and the internal organs of the dead fish. The serological types of the bacteria isolated were identical with those used for inoculation in the respective experiments. These facts suggest that bacteria discharged from the inoculated fish might gain entrance to control fish through bites.

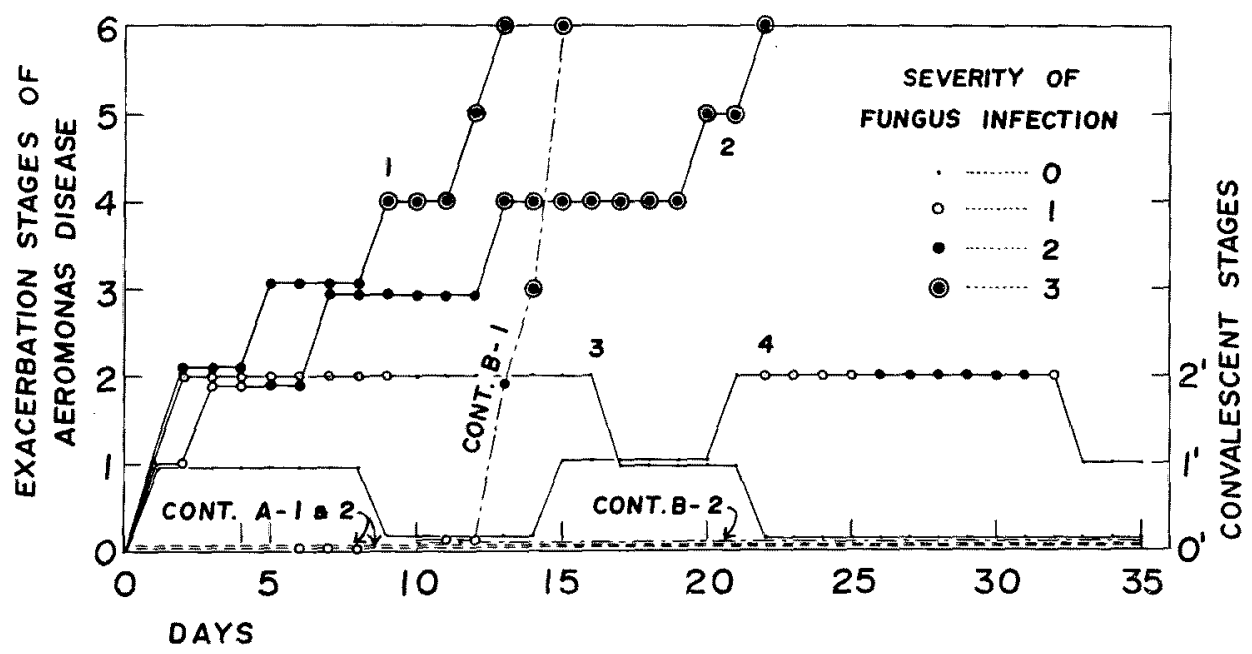

Fig. 2. Progression of "Aeromonas disease" and fungus infection in eels inoculated with Aeromonas liquefaciens (strain T-ET).

See text for explanation of numerical indices for stages of "Aeromonas disease" and for degrees of severity of fungus infection. 1 4, experimental fish.

The remaining 6 control-A fish and 2 control-B fish survived the experiments without showing any signs of fungus infection from beginning to end. These 8 fish 
and the 7 fish which were temporarily fungused were examined for the presence of A. liquefaciens at the end of the experiment, with the result that they were all negative.

Table 5 shows the frequency with which each of the 40 conditions of fish, expressed by combinations of the 10 stages of "Aeromonas disease" and the 4 degrees of severity of fungus infection, was recorded of both experimental and control fish by daily observation over a period of 35 days. It can be seen from the table that there is an appreciable parallelism between severity of "Aeromonas disease" and that of fungus infection.

Table 5. Relation between severity of a disease caused by the inoculation of Aeromonas liquefaciens and that of fungus infection.

\begin{tabular}{|c|c|c|c|c|c|c|c|c|c|c|}
\hline \multirow{2}{*}{$\begin{array}{l}\text { Severity index* } \\
\text { of } \\
\text { fungus infection }\end{array}$} & \multicolumn{10}{|c|}{ Stages of Aeromonas disease** } \\
\hline & 0 & $0^{\prime}$ & 1 & $1^{\prime}$ & 2 & $2^{\prime}$ & 3 & 4 & 5 & 6 \\
\hline 0 & 448 & 95 & 47 & 28 & 17 & - & - & - & - & - \\
\hline 1 & 50 & - & 29 & 8 & 73 & 8 & - & - & - & - \\
\hline 2 & -- & - & 2 & - & 46 & 5 & 38 & 5 & - & - \\
\hline 3 & - & - & - & - & 3 & - & 13 & 27 & 19 & 17 \\
\hline
\end{tabular}

*,** Explanation in text. Note that criteria different from those in Table 3 and 4 are used in this table.

\section{Discussion}

Almost all the diseased eels collected from eel-culturing ponds where epizootics of the so-called fungus disease were prevailing showed some or all of the characteristic external and internal symptoms, i. e., formation of eroded, sometimes bloodcolored areas and extensive necrotic areas on the surface of the body; development of petechiae or ecchymoses on the skin; reddening of the anal fin, pectoral fin, belly or vent; congestion of the liver, spleen or kidney; inflammation of the intestine or stomach. Most of these fish had considerable fungus on their skin lesions. It is worth noticing, however, that about one fifth of the diseased fish examined showed no signs of fungus infection. This indicates indubitably that fungus is not a primary etiological agent.

The above-mentioned symptoms are similar to those of "red fin disease ") and "Süsswasserrotseuche" "8) of eels, which are both known to be caused by Aeromonas punctata (A synonym of $A$. liquefaciens $\left.{ }^{6}\right)$. As was to be expected, A. liquefaciens was regularly isolated from the skin lesions and/or the viscera of all the diseased fish examined except two with very slight symptoms. The fact that almost all fungus-diseased eels harboured $A$. liquefaciens and exhibited symptoms characteristic of Aeromonas infection (hemorrhagic septicemia) suggests that the primary infecting organism of the epizootic in question may be $A$. liquefaciens. 
It was proved by experiment that Aeromonas-infected eels became susceptible to fungus infection; that is, when eels inoculated intramuscularly with $A$. liquefaciens were exposed to Saprolegnia parasitica, they became very easily infected with the fungus. In addition, an appreciable parallelism was found between severity of "Aeromonas disease" and that of fungus infection.

It seems reasonable to conclude from these results that $A$. liquefaciens is the primary etiological agent of the epizootic of eels which has commonly been called "fungus disease".

The present authors are indebted to Mr. IIzuka of Hamana Branch Station of Shizuoka Prefectural Fisheries Experimental Station for his able collaboration.

\section{Summary}

Diseased eels collected from eel-culturing ponds where the so-called fungus disease was prevailing presented mostly external and internal symptoms characteristic of Aeromonas infection. While about one fifth of the diseased eels examined showed no signs of fungus infection.

Aeromonas liquefaciens was regularly isolated from the skin lesions and/or the viscera of diseased fish.

Eels inoculated intramuscularly with this bacterium became easily infected with Saprolegnia parasitica and an appreciable parallelism was found between severity of "Aeromonas disease" and that of fungus infection.

The conclusion, therefore, is that A. liquefaciens is the primary causative agent of the so-called fungus disease of eels.

\section{References}

1) EguSA, S.: This journal, 31, 517-526 (1965).

2) Breed, R. A., E. D. G. MurRy, and N. R. Smith: Bergey's Manual of Determative Bacteriology. 7th ed. The Williams and Wilkens Co., Baltimore 1094 p. (1957).

3) Ewing, W. H., R. H. Hugh, and J. G. Johnson: Public Health Service publication. U. S. Govt. Printing Office. Washington D. C. 37 p. (1961).

4) EDDy, B. P.: Jour. Appl. Bact., 23, 216-249 (1960).

5) Bullock, G. L.: Appl. Microbiology, 9, 587-590 (1961).

6) Snieszko, S. F., and G. L. Bullock: U. S. Fish and Wildlife Serv., Fishery Leaflet 459 , 7 p. (1962).

7) Hoshina, T.: Jour. Tokyo Univ. Fisheries, Special ed., 6, 1-104 (1962).

8) SchäPERClaus, W.: Z. Fischerei, 28, 289-370 (1930). 